J. Amer. Soc. Hort. Sci. 116(5):802-806. 1991

\title{
Leachate Electrical Conductivity and Growth of Potted Poinsettia with Leaching Fractions of
}

\section{0 to 0.4}

\author{
Catherine S.M. Ku ${ }^{1}$ and David R. Hershey ${ }^{2}$ \\ Department of Horticulture, University of Maryland, College Park, MD 20742-5611 \\ Additional index words. leaching, groundwater, fertigation, irrigation, $\mathrm{pH}$, salinity, soluble salts, Euphorbia pulcherrimu
}

\begin{abstract}
Poinsettias (Euphorbia pulcherrima Willd. ex Klotzsch 'V-14 Glory') were grown in a greenhouse for 70 days in 1.3 liters of medium $(13 \mathrm{~cm}$ deep in $15-\mathrm{cm}$ pots) with a leaching fraction (LF) of $\approx 0,0.1,0.2$, or 0.4 . Plants were fertigated with $300 \mathrm{mg}$ N/liter from $20 \mathrm{~N}-4.4 \mathrm{P}-16.6 \mathrm{~K}$. The electrical conductivity (EC) of the fertigation solution was $2.1 \mathrm{dS} \cdot \mathrm{m}^{-1}$. The leachate EC increased from $2 \mathrm{dS} \cdot \mathrm{m}^{-1}$ initially to plateaus of $\approx 6,9$, and $15 \mathrm{dS} \cdot \mathrm{m}^{-1}$ for $\mathrm{LFs}$ of 0.4, 0.2, and 0.1, respectively. Poinsettia height, shoot fresh and dry mass, and leaf and bract areas were not significantly different among the LF treatments. Leachate pH decreased from 6.1 initially to 5.1 at the end, but there was no significant difference among the $\mathrm{LF}$ treatments. The $\mathrm{EC}$ of a saturated medium extract $\left(\mathrm{EC}_{\mathrm{e}}\right)$ was between $17 \%$ and $48 \%$ higher in the lower third of the medium than in the middle third. The difference was greater with a lower LF. The EC, was 8.9, 7.3, 5.2, and $3.4 \mathrm{dS} \cdot \mathrm{m}^{-1}$ in the lower third of the pot for a $\mathrm{LF}$ of $0,0.1,0.2$, and 0.4 , respectively. Under conditions of this study, container poinsettias required no leaching.
\end{abstract}

Leaching water and dissolved substances out the bottom of the container has received major attention recently because it wastes water and fertilizer and may contaminate groundwater with fertilizers and pesticides (Biernbaum and Fonteno, 1989). One beneficial aspect of leaching is that it removes excess salts and prevents salinity buildup in the rootzone (Richards, 1954). Therefore, environmentally sound crop management dictates that the negative aspects of leaching should be minimized by providing only enough leaching to control salinity. This strategy has been developed extensively for field crops using the concepts of the LF and leaching requirement (LR) (Ayers and Westcot, 1976). The LF is defined as [volume of solution leached (Vi)]/[volume of solution applied to the crop $\left.\left(\mathrm{V}_{\mathrm{a}}\right)\right]$. The LF needed to achieve a specific level of soil salinity is defined as the LR, which is calculated as follows: $\mathrm{LR}=\mathrm{EC}_{\mathrm{a}} / \mathrm{EC}_{1}$, where $\mathrm{EC}$, is the $\mathrm{EC}$ of the applied solution, and $\mathrm{EC}_{1}$ is the $\mathrm{EC}$ of the leachate (Richards, 1954).

The application of the concepts of LF and LR to containergrown crops has not been intensively researched. One text on greenhouse management (Hanan et al., 1978) has a table of LR values, and a manual about azaleas briefly discusses LR (Kofranek and Lunt, 1975), but most references on greenhouse crops say nothing about LR. Typically, such texts recommend that some leaching occur without indicating the amount of leaching required, or they recommend a particular LF for all crops, e.g., $10 \%$ or $\mathrm{LF}=0.1$ (Langhans, 1980). However, such recommendations are broad generalizations that do not seem to be based on specific research with container crops and that will not apply in many situations. The LR depends on several factors, including crop salinity tolerance, the salt content of the irrigation solution, and the crop yield reduction, due to salinity, that can be tolerated by the grower (Richards, 1954).

The LF is-a key variable in container-plant research but often is not specified or an unrealistically high LF is used. Many

Received for publication 3 July 1990. Scientific Article no. A6046, Contribution no. 8207 of the Maryland Agr. Expt. Sta. The cost of publishing this paper was defrayed in part by the payment of page charges. Under postal regulations, this paper therefore must be hereby marked advertisement solely to indicate this fact.

'Graduate Research Assistant.

${ }^{2}$ Assistant Professor, to whom reprint requests should be addressed. studies of salt or fertilizer leaching in containers have used unplanted growing media at container capacity and a LF of $\approx 1$ (Kerr and Hanan, 1985; Marconi and Nelson, 1984; Yeager and Barrett, 1986). In actual greenhouse production using surface irrigation, container plants are irrigated when the medium is below container capacity (the LF is well below 1) and leaching occurs at every irrigation. Also, the plants absorb a portion of the added fertilizer salts. Some leaching studies have used container-grown crops but failed to report the LF (Gob and Haynes, 1977; Haynes, 1982). There have been few studies where the LF was measured throughout production of a container-grown crop in a greenhouse. Cox (1985) grew geraniums in containers with an overall LF of 0.43 to 0.59 . Hershey and Paul (1982) grew potted chrysanthemums and leached weekly for an overall LF of $\approx 0.27$.

Although rarely measured, the LF often appears to be well above the LR. For example, Sciaroni et al. (1977) demonstrated that a commercial grower of potted chrysanthemums could reduce their irrigation by $75 \%$ and their fertilizer application by $94 \%$ and still not reduce crop growth. Their study indicated that in typical commercial production, the LF was $\approx 0.75$ when the LR was apparently $\approx 0$. More recently, Lieth and Burger (1989) confirmed this work by demonstrating that a tensiometer-controlled drip-irrigation system grew excellent container chrysanthemums with a LF of 0 .

We evaluated growth of container-grown poinsettia with the LF carefully controlled in a realistic range of 0 to 0.4 and tested the applicability of the LR to container-grown crops by closely monitoring leachate $\mathrm{EC}$ and measuring medium $\mathrm{EC}_{\mathrm{c}}$ at harvest.

\section{Materials and Methods}

Rooted terminal cuttings of 'V-14 Glory' poinsettia were planted one per 15-cm-diameter standard plastic pot (Kord Corp., Lugott, S.C.). Medium bulk volume was 1.3 liters/pot, and medium depth was $13 \mathrm{~cm}$. Water content at container capacity determined on five unplanted pots was $65 \%$ of the bulk volume.

Abbreviations: EC, electrical conductivity $\mathrm{EC}_{\mathrm{a}}, \mathrm{EC}$ of the applied solution; $\mathrm{EC}_{c}, \mathrm{EC}$ of a saturated medium extract; ET, evapotranspiration; LF, leaching fraction; LR, leaching requirement; $M_{w}$, mass of pot after irrigation when at container capacity $\mathrm{M}_{b}$, mass of pot before irrigation. 
The medium was Pro-Mix BX (Premier Brands, New Rochelle, N.Y.). Pro-Mix BX consists of sphagnum peat, vermiculite, and perlite amended with dolomitic limestone, calcium nitrate, superphosphate, fritted trace elements, and a wetting agent. Pots were spaced on $38 \times 38-\mathrm{cm}$ centers on raised benches in a glasshouse where the air minima were $\approx 18 \mathrm{C}$ at night and $21 \mathrm{C}$ during the day. Plants were grown under natural photoperiods.

Leaching fraction treatments of $0,0.1,0.2$, and 0.4 were maintained by careful manual irrigation coupled with weighing planted pots before and after irrigation, calculating the irrigation volume required to produce the desired LF, and determining the actual volume of leachate. Pots were weighed on a batteryoperated, portable electronic balance with a capacity of $3 \mathrm{~kg} \pm$ $2 \mathrm{~g}$ (Cole-Parmer, Chicago). Except for the initial irrigation with tap water, plants were irrigated with $300 \mathrm{mg}$ N/liter from Peter's Peat-Lite Special (Peters Fertilizers, Fogelsville, Pa.) with 20N4.4P-16.6K-0.15Mg-0.1Fe-0.56Mn-0.2B-0.162Zn-0.1Cu-

$0.1 \mathrm{Mo}$. The fertilizer contained $60 \%$ nitrate-N and $40 \%$ ammonium-N.

Treatments were replicated five times with one plant per replication. Pots were in a completely randomized design. Each pot was set on top of an empty, overturned pot (Kord) that was inside a 2-liter plastic specimen container (VWR Scientific, Philadelphia). At each irrigation, the leachate ran into the specimen container. When leaching stopped, the leachate was poured into a graduate cylinder for volume measurement.

The study began 10 Oct. 1988 by irrigating the pots with tap water to bring them to container capacity. The initial mass of the pot at container capacity was determined and designated $\left(\mathrm{M}_{\mathrm{a}}\right)$. There were 20 irrigations and leachings during the 10week study, every 3 to 5 days as needed. Just before irrigation, the water content of the medium averaged $42 \%$ of the bulk volume, which was $64 \%$ of the moisture content at container capacity. The volumes applied and leached are shown in Fig. 1. At each irrigation and leaching, the mass of the pot just before irrigation $\left(\mathrm{M}_{\mathrm{b}}\right)$ was measured and used to determine the evapotranspiration (ET) since the previous irrigation by $\mathrm{ET}=\left(\mathrm{M}_{\mathrm{a}}\right.$ $\left.-\mathrm{M}_{\mathrm{b}}\right)$. The volume of irrigation solution to apply was then calculated by: $\mathrm{V}_{\mathrm{a}}=(\mathrm{LF} \times \mathrm{ET}) /(1-\mathrm{LF})+\mathrm{ET}$. For example, if $\mathrm{LF}=0.2$ and $\mathrm{ET}=80 \mathrm{ml}$, then $\mathrm{V}_{\mathrm{a}}=[(0.2 \times 80) /(1-$ $0.2)]+80$ or $\mathrm{V}_{\mathrm{a}}=100$. This calculated volume of solution was then applied. After leaching stopped, Ma was measured and the actual volume of leachate determined using a graduate cylinder.

The leachate $\mathrm{pH}$ and EC were measured using pocket meters (Hershey; 1988a, 1988b). All EC data were reported at the standard temperature of $25 \mathrm{C}$. The $\mathrm{EC}$ of the irrigation water and fertilizer solution was $0.3 \mathrm{dS} \cdot \mathrm{m}^{-1}$ and $2.1 \mathrm{dS} \cdot \mathrm{m}^{-1}$, respectively. To increase the accuracy of the pocket EC meter data, the raw data $\left(\mathrm{EC}_{\mathrm{r}}\right)$ were corrected using a correlation between nine KCI standards of known EC and the pocket meter readings $\left(r^{2}=0.999\right)$ (Hershey, 1988a). The nine EC standards encompassed the entire range of the raw data. The mean daily alkalinity of the irrigation water for 1988 was $70 \mathrm{mg} \mathrm{CaCO}_{3} / \mathrm{liter}$, with a range of 48 to $92 \mathrm{mg} \cdot \operatorname{liter}^{-1}$ (B. Fisher, personal communication).

The study ended on 16 Dec. Plant heights were measured from the top of the pot to the top of the canopy, and the stems were cut at the medium surface. Leaf, bract, and stem fresh masses were measured to the nearest $0.1 \mathrm{~g}$ on an electronic balance, and areas of leaves and bracts, petiole included, were determined with an area meter (LI-COR, Lincoln, Neb.). After
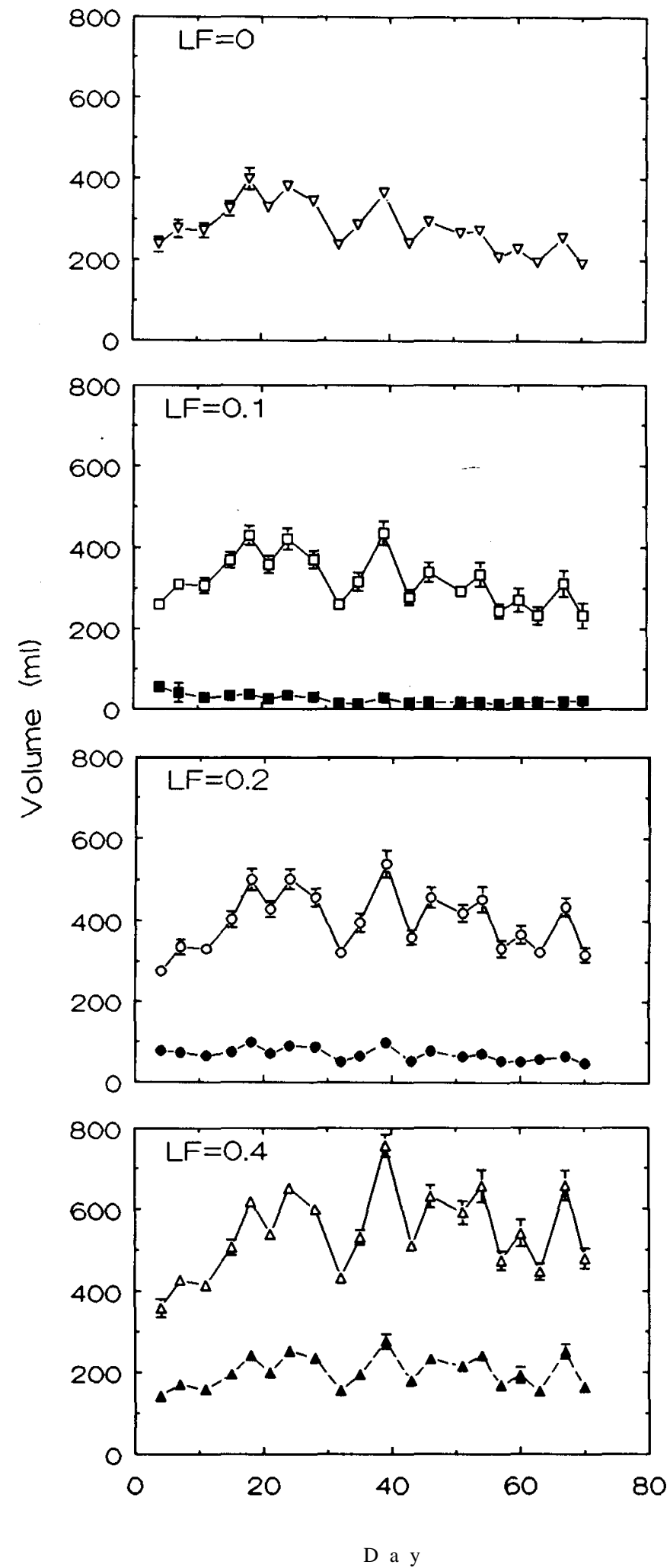

Fig. 1. Fertigation solution volumes applied (open symbols) for LFs $0,0.1,0.2$, and 0.4 , and actual volumes leached (filled symbols) for LFs 0.1, 0.2, and 0.4. Each point represents a mean $\pm \mathrm{SE}, \mathrm{n}=$ 5. If not shown, error bar lies with symbols.

oven-drying at 40C, dry masses of leaves, bracts, and stems were determined.

The growing medium was divided into upper, middle, and 
lower thirds, based on height, and a saturated medium sample prepared using deionized water (Bunt, 1988). A vacuum extract of the saturated medium was then obtained using the apparatus of Hershey (1989), and the EC and $\mathrm{pH}$ of the extract were determined and designated $\mathrm{EC}_{\mathrm{e}}$ and $\mathrm{pH}_{\mathrm{e}}$.

Graphs and regressions were prepared with an IBM personal computer using SlideWrite Plus, version 3.1 (Advanced Graphics Software, Sunnyvale, Calif.). Sample standard errors of the mean were calculated using Lotus 1-2-3, version 2.01 (Lotus Development Corp., Cambridge, Mass.). Analysis of variance was calculated using SAS (SAS Institute, Cary, N.C.).

\section{Results and Discussion}

There was no significant difference due to LF for any plant measurements at harvest. Across all treatments, mean plant height was $23 \mathrm{~cm}$, mean leaf area was $1500 \mathrm{~cm}^{2}$, mean bract area was $2900 \mathrm{~cm}^{2}$, mean shoot fresh mass was $113 \mathrm{~g}$, and mean shoot dry mass was $16.2 \mathrm{~g}$.

Calculation of the LF at each irrigation using the data in Fig. 1 revealed that the desired LF treatments were not exactly attained (Fig. 2). The LF decreased slightly with time. This is most evident for the $0.4 \mathrm{LF}$. One reason for this decline is related to the $M_{a}$ data (Fig. 3). For $L F=0$, there is a decrease in $\mathrm{M}_{\mathrm{a}}$ with time from an initial 1260 to $1090 \mathrm{~g}$. A major cause of this decrease was that the equation used to calculate the volume to apply at each irrigation ignored the increase in plant mass. Thus, ET was underestimated, and the pot was not brought back to container capacity at each irrigation. To overcome the problem of underattaining the desired LF in future studies, the plant mass increase needs to be included when calculating the volume of solution to apply. Comparing observed and predicted leachate volumes and adjusting future irrigation volumes accordingly would solve the problem.

The total decline in $\mathrm{M}_{\mathrm{a}}$ of $170 \mathrm{~g}$ for $\mathrm{LF}=0$ was more than the top fresh mass at harvest of $107 \mathrm{~g}$. This difference can be partly accounted for by the increase in root fresh mass, but also by medium shrinkage and filling of medium pores with roots, which would lead to a decrease in container capacity. Fonteno et al. (1981) measured such decreases in water-holding capacity of the medium during cropping of poinsettia.

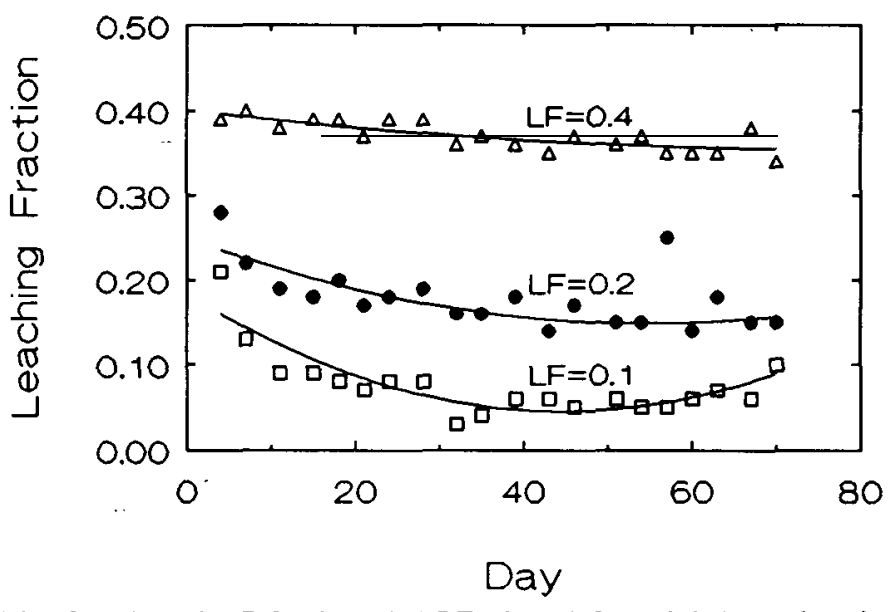

Fig. 2. Actual LF for intended LFs $0.1,0.2$, and 0.4. Each point represents a mean, $\mathrm{n}=5$. Second-degree polynomial regressions ( $\mathrm{n}$ $=100)$ are $\mathrm{LF}=0.00007 \times \mathrm{day}^{2}-0.00624 \times$ day +0.184 , $r^{2}=0.654$, for $\mathrm{LF}=0.1 ; \mathrm{LF}=0.000034 \times$ day $^{2}-0.00371 \times$ day $+0.250, r^{2}=0.609$, for $\mathrm{LF}=0.2$; and $\mathrm{LF}=0.00000782$ $\times$ day $^{2}-0.00121 \times$ day $+0.401, r^{2}=0.291$, for $L F=0.4$.
By harvest, M, for LF of 0.1 and above had increased 30 to $50 \mathrm{~g}$ over the initial value, not enough to represent the plant shoot mass gain of $113 \mathrm{~g}$. Since pots were brought back to container capacity with each irrigation and leaching for $0.1,0.2$, and $0.4 \mathrm{LF}$, the smaller than expected $\mathrm{M}_{\mathrm{a}}$ increase was probably due to a decrease in container capacity over time (Fonteno et al., 1981).

The daily ET per pot varied greatly (Fig. 4) but was generally similar among the four LF treatments. Therefore, the daily ET was averaged over all LF treatments. ET was only measured at each leaching, so there are ET values for only 20 dates. These values were averaged over the 3 to 5 days between irrigations. The total ET during the 70-day experiment was between 5600 and $6800 \mathrm{ml}$ (Table 1). ET calculated by differences in pot mass was slightly less than ET calculated based on volumes applied and leached. The maximum difference was $<5 \%$.

The leachate EC increased until a plateau was approached or reached (Fig. 5). The plateau was most obvious for $\mathrm{LF}=0.4$

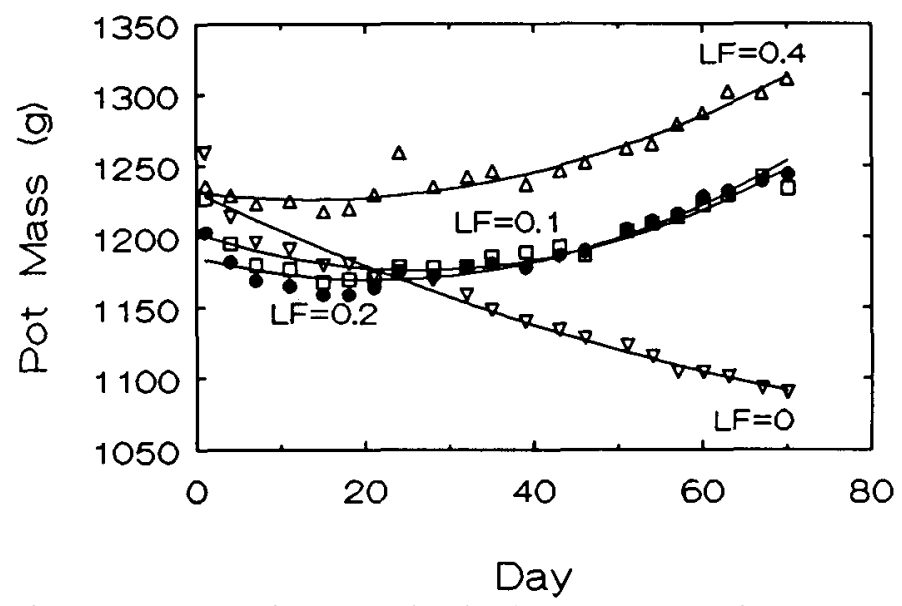

Fig. 3. Pot mass after fertigation (PM) for LFs $0,0.1,0.2$, and 0.4 . Each point represents a mean, $\mathrm{n}=5$. Second-degree polynomial regressions $(\mathrm{n}=105)$ are $\mathrm{PM}=0.0117 \times$ day $^{2}-2.81 \times$ day $+1230, r^{2}=0.248$, for $\mathrm{LF}=0 ; \mathrm{PM}=0.0373 \times \mathrm{day}^{2}-1.96$ $\times$ day $+1200, r^{2}=0.216$, for $\mathrm{LF}=0.1 ; \mathrm{PM}=0.0351 \times$ day $^{2}$ $-1.48 \times$ day $+1180, r^{2}=0.356$, for $\mathrm{LF}=0.2$; and $\mathrm{PM}=$ $0.0269 \times$ day $^{2}-0.719 \times$ day $+1230, r^{2}=0.239$, for $L F=$ 0.4 .

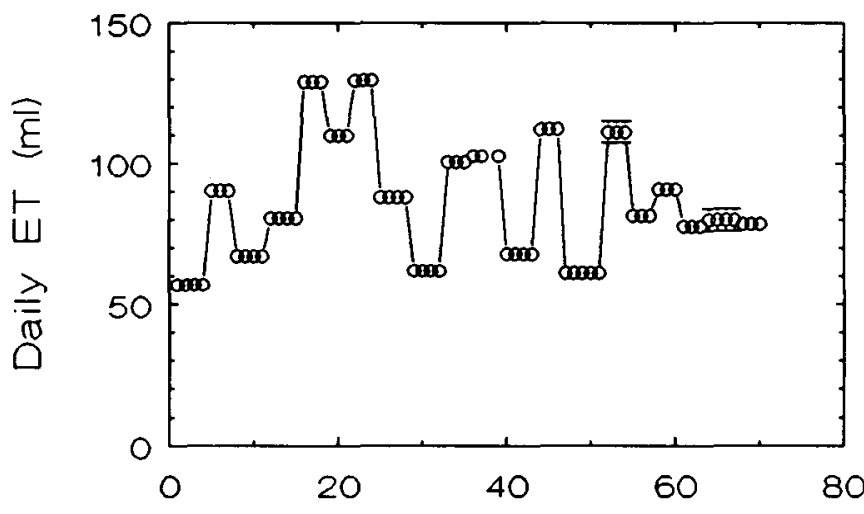

\section{Day}

Fig. 4. Mean ET for LFs $0,0.1,0.2$, and 0.4. Each point represents a mean $\pm S E(n=20)$ over 3 to 5 days since ET was measured only every 3 to 5 days. Data for all four treatments were combined since ET was similar for all. If not shown, error bar lies within symbol. 
Table 1. Overall volumes of nutrient solution applied and leached, LF, and ET from potted poinsettia. ${ }^{2}$

\begin{tabular}{llclc}
\hline \hline & \multicolumn{4}{c}{ LF } \\
\cline { 2 - 5 } Measurement & \multicolumn{1}{c}{0} & \multicolumn{1}{c}{0.1} & \multicolumn{1}{c}{0.2} & 0.4 \\
\hline Total solution applied $(\mathrm{ml})$ & $5,600 \pm 144$ & $6,380 \pm 397$ & $7,970 \pm 409$ & $10,800 \pm 349$ \\
Total solution leached $(\mathrm{ml})$ & 0 & $489 \pm 65$ & $1,380 \pm 65$ & $4,010 \pm 126$ \\
Overall LF & 0 & $0.0779 \pm 0.0019$ & $0.173 \pm 0.0014$ & $0.370 \pm 0.0012$ \\
ET $(\mathrm{g})^{y}$ & $5,590 \pm 137$ & $5,740 \pm 357$ & $6,370 \pm 327$ & $6,493 \pm 211$ \\
ET $(\mathrm{ml})^{\mathbf{x}}$ & $5,600 \pm 144$ & $5,890 \pm 374$ & $6,590 \pm 345$ & $6,810 \pm 224$ \\
\hline
\end{tabular}

${ }^{z}$ Data represent mean $\pm \mathrm{SE}, \mathrm{n}=5$.

${ }^{y}$ Calculated on mass basis using mass of pots.

${ }^{x}$ Calculated on volume basis using volume applied and volume leached.

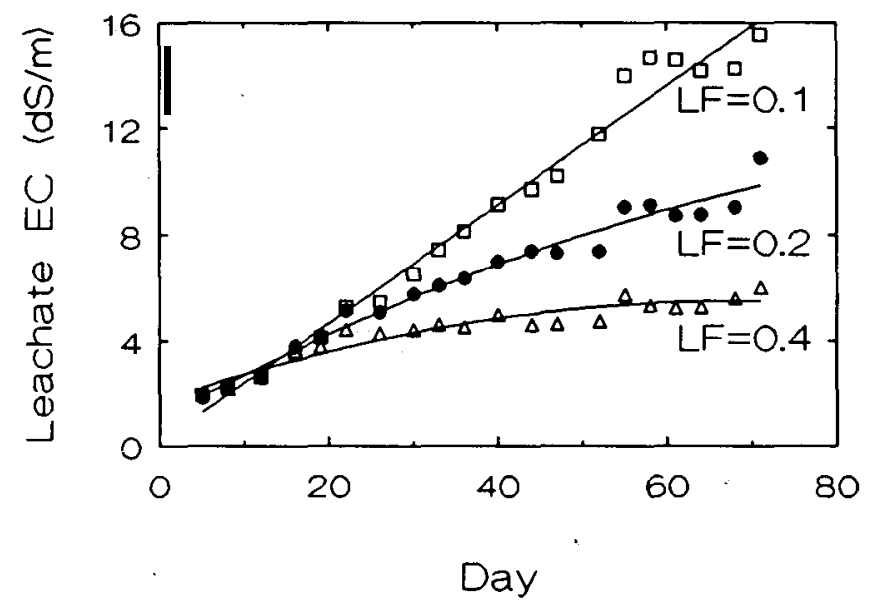

Fig. 5. Leachate EC for LFs 0.1, 0.2, and 0.4. Each point represents a mean, $\mathrm{n}=5$. Second-degree polynomial regressions $(\mathrm{n}=100)$ are $\mathrm{EC}=-0.000000275 \times \mathrm{day}^{2}+0.224 \times$ day $+0.185, r^{2}=$ 0.945, for $\mathrm{LF}=0.1 ; \mathrm{EC}=-0.000684 \times \mathrm{day}^{2}+0.172 \times$ day $+1.06, r^{2}=0.927$, for LF $=0.2$; and $\mathrm{EC}=-0.000793 \times \mathrm{day}^{2}$ $+0.110 \times$ day $+1.72, r^{2}=0.874$, for $L F=0.4$

since the plateau EC was inversely related to the LF. The plateau EC represents a steady state, where the salt added to the container about equals the salt leaving the container. This steadystate conditions an assumption of the LR equation (Richards, 1954). Similar plateau-shaped curves for leachate nitrate level were found by Hershey and Paul (1982). The higher the LF, the sooner the plateau was reached, $\approx 20,40$, and 53 days for $0.4,0.2$, and $0.1 \mathrm{LF}$, respectively.

For all LF treatments, leachate $\mathrm{pH}$ decreased during the experiment from $\approx 16.1$ initially to 5.1 just before harvest. Medium pH. at harvest decreased slightly as LF increased (Fig. 6). The medium $\mathrm{pH}_{\mathrm{e}}$ at harvest was $\approx 0.5$ units less in the upper than in the lower third of the medium (Fig. 6). The decrease in leachate $\mathrm{pH}$ was probably due to physiological acidity (Moore, 1974). The increase in medium $\mathrm{pH}_{\mathrm{e}}$ from the upper to middle to lower third of the pot was possibly caused by adsorption of ammonium to the medium.

The medium $\mathrm{EC}_{\mathrm{e}}$ increased as LF decreased (Fig. 6). The lower the $\mathrm{LF}$, the greater the $\mathrm{EC}_{\mathrm{e}}$ increase from the middle to lower third of the medium. The $\mathrm{EC}_{\mathrm{e}}$ was $2.7,2.0,1.1$, and 0.5 $\mathrm{dS} \cdot \mathrm{m}^{-1}$ higher in the lower third than in the middle third for a LF of $0,0.1,0.2$, and 0.4 , respectively (Fig. 6). This pattern of $\mathrm{EC}_{\mathrm{e}}$ reflects the piston displacement of solution in the medium by the applied solution and indicates that the upper portion of the medium can be substantially lower in salt than the lower portion, even with no leaching (Ayers and Westcot, 1976). This situation may provide a strategy for growers to minimize leach-

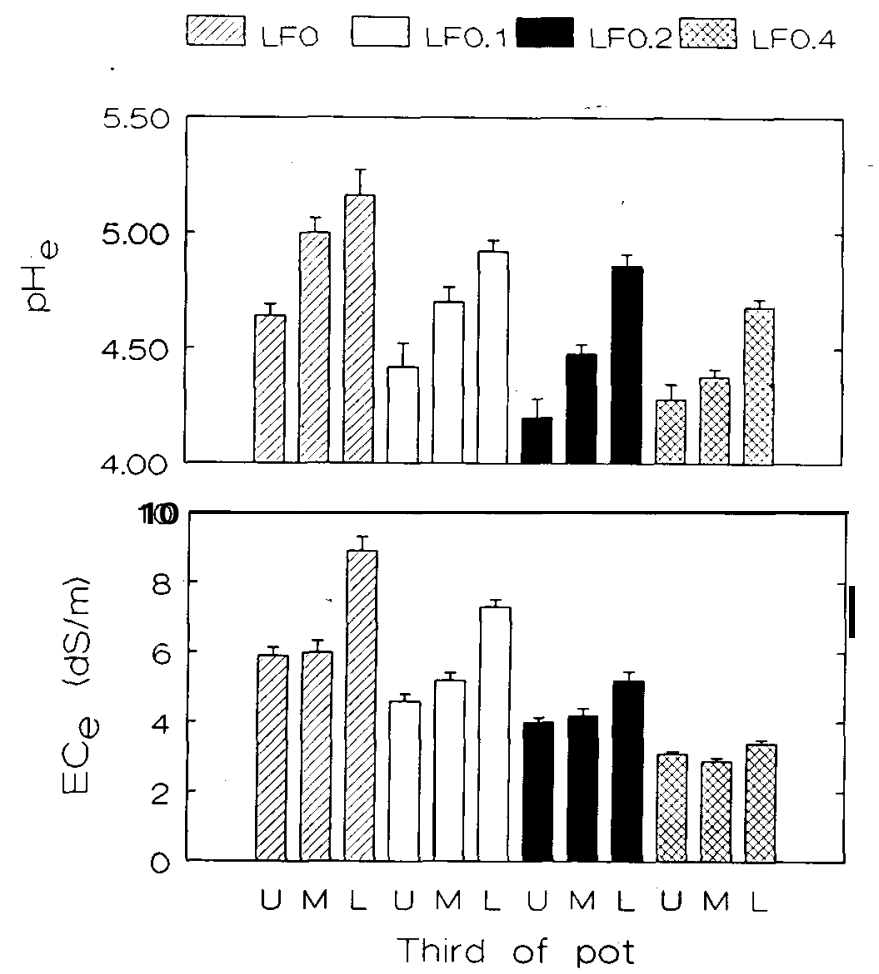

․ 6. Growing medium $\mathrm{pH}_{\mathrm{e}}$ and $\mathrm{EC}_{\mathrm{e}}$ at harvest for the upper $(\mathrm{U})$, niddle (M), and lower (L) third of the medium. Each bar represents I mean, $\mathrm{n}=5$. Error bar is SE.

ing yet allow roots to grow in the upper, less saline portion of the container. The reverse occurs in subirrigation, where salts accumulate in the upper layers of the container.

The LR equation can be used to estimate the LF needed. Using the $\mathrm{EC}_{\mathrm{a}}$ of $2.1 \mathrm{dS} \cdot \mathrm{m}^{-1}$ and steady-state $\mathrm{EC}_{1}$ values of 15 , 9 , and $6 \mathrm{dS} \cdot \mathrm{m}^{-1}$ gives a LR of $0.14,0.23$, and 0.35 , respectively, for LFs of $0.1,0.2$, and 0.4 . The LR calculation seems to work fairly well since the actual LFs were $0.08,0.17$, and 0.37 , respectively (Table 1 ). However, the equation is not useful for predicting the LF needed in a particular situation because crop salinity tolerance is typically expressed in terms of the EC associated with a particular crop yield, e.g., 90\% of maximum, rather than with EC, (Ayers and Westcot, 1976; Maas and Hoffman, 1977). Hartmann et al. (1988) provided $\mathrm{EC}_{\mathrm{e}}$ data of this type for nine greenhouse flower crops. Poinsettia yields of $90 \%$, $75 \%$, and $50 \%$ of maximum were associated with medium EC. values of $2.5,6.5$, and $12.0 \mathrm{dS} \cdot \mathrm{m}^{-1}$ respectively. Poinsettia is one of the most salinity-tolerant greenhouse-grown container crops.

Using such $\mathrm{EC}_{\mathrm{e}}$ standards and $\mathrm{EC}_{\mathrm{a}}$ to determine the $\mathrm{LR}$ has 
been clone by Ayers and WestCot (1976) for field crops. They suggest that LR for surface irrigation be calculated using the following equation: $\mathrm{LR}=\mathrm{EC}_{\mathrm{w}} /\left(5 \times \mathrm{EC}_{\mathrm{e}}-\mathrm{EC}_{\mathrm{w}}\right)$, where $\mathrm{EC}_{\mathrm{w}}$ is the irrigation water EC. Solving for $\mathrm{LR}$ using $\mathrm{EL}_{\mathrm{w}}=\mathrm{EC}_{\mathrm{a}}$ $=2.1 \mathrm{dS} \cdot \mathrm{m}^{-1}$ and the $\mathrm{EC}_{\mathrm{e}}$ values in the upper third of the medium of $4.6,4.0$, and $3.1 \mathrm{dS} \cdot \mathrm{m}^{-1}$ gives LR values of 0.1 , 0.12 , and 0.16 , respectively, for LFs of $0.08,0.17$, and 0.37 . The calculated LR is a reasonable prediction at the lowest LF, but the agreement is lessened as the LF increases. Thus, the equation does not seem to apply to fertigated, container-grown poinsettia:

Ayers and Westcot (1976) also presented a second equation for high-frequency sprinkler or near daily drip irrigation, situations possibly more analogous to frequent irrigation of containers. This equation is $\mathrm{LR}=\mathrm{EC}_{\mathrm{w}} /\left(2 \times \operatorname{maxEC} \mathrm{EC}_{\mathrm{e}}\right.$, where $\operatorname{maxEC}_{\mathrm{e}}$ is the $\mathrm{EC}_{\mathrm{e}}$ for a $0 \%$ yield. Using the poinsettia $\mathrm{EC}_{\mathrm{e}}$ data of Hartmann et al. (1988) to extrapolate to $0 \%$ yield gives a $\operatorname{maxEC}_{\mathrm{e}}$ of $23.9 \mathrm{dS} \cdot \mathrm{m}^{-1}$. The calculated LF is 0.04 , which means virtually no leaching is needed. This result seems reasonable based on the lack of statistically significant growth differences achieved in this study, yet is much lower than generally recommended for fertigated container plants. This difference may be due to the relatively high salinity tolerance of poinsettia.

Crop salinity tolerance may differ depending on plant and environmental conditions (Ayers and Westcot, 1976). Typically, salinity tolerance is determined by constant irrigation with solutions of various EC values. This is different from what typically occurs in container crops, where the leachate EC increases until a plateau or steady-state level is attained (Fig. 5). Leaching of container-grown poinsettia under fairly typical commercial conditions of surface fertigation with a low-EC irrigation water (Ayers, 1977) appeared unnecessary to prevent salinity injury. These results agreed with an equation that predicted that a LR for optimal poinsettia growth was 0.04 .

Applying the concepts of LF and LR to container irrigation management should reduce the amount of leaching, which would decrease the amount of water and fertilizer needed for greenhouse crop production. Reducing the fertilizer concentration in the irrigation solution is also a good strategy to reduce leaching losses. This research used a relatively high fertigation rate of $300 \mathrm{mg}$ N/liter, and the high leachate $\mathrm{EC}$ and $\mathrm{EC}_{\mathrm{e}}$ indicated that excess fertilizer was leaching from and accumulating in the container.

These simple concepts, which have been known since the 1950 s, should be more widely tested for greenhouse crop management. By measuring the $\mathrm{EC}$ of the irrigation solution $\left(\mathrm{EC}_{\mathrm{w}}\right)$ and using $\operatorname{maxEC}_{\mathrm{e}}$ for a particular crop, the LR, or LF needed to prevent salinity injury, might be determined using the equation: $\mathrm{LR}=\mathrm{EC}_{\mathrm{w}} /\left(2 \times \operatorname{maxEC}_{\mathrm{e}}\right.$. This approach appears promising and could be easily implemented in a commercial situation. However, additional research with other crops is required to validate this approach.

\section{Literature Cited}

Ayers, R.S. 1977. Quality of water for irrigation. J. Irr. Drainage Div. Amer. Soc. Civil Eng. 103:135-154.
Ayers, RS. and D. W. WestCot. 1976. Water quality for agriculture. Irrigation and drainage paper 29. Food \& Agr. Organization of the United Nations, Rome.

Biernbaum, J. and W. Fonteno. 1989. Minimize groundwater contamination. Greenhouse Grower 7(2):90-92, 94-95.

Bunt, A.C. 1988. Media and mixes for container-grown crops. Unwin Hyman, Boston.

Cox, D.A. 1985. Nitrogen recovery by seed geranium as influenced by nitrogen source. HortScience 20:923-925.

Fonteno, W. C., D.K. Cassel, and R.A. Larson. 1981. Physical properties of three container media and their effect on poinsettia growth.

J. Amer. Soc. Hort. Sci. 106:736-741.

Goh, K.M. and R.J. Haynes. 1977. Evaluation of potting media for commercial nursery production of container plants III. Effects of media, fertilizer nitrogen, and a vitrification inhibitor on soil nitrification and nitrogen recovery of Callistephus chinensis (L.) 'Pink Princess'. N.Z. J. Agr. Res. 20:383-393.

Hanan, J. J., W.D. Honey, and K.L. Goldsberry. 1978. Greenhouse management. Springer-Verlag, New York.

Hartmann, H. T., A.M. Kofranek, V.E. Rubatsky, and W.J. Flocker. 1988. Plant science: Growth, development, and utilization of cultivated plants. Prentice Hall, Englewood Cliffs, N.J.

Haynes, R.J. 1982. Leaching losses of nutrients and yield and nutrient uptake by container-grown begonia as affected by lime and fertilizer applications to a peat medium. J. Sci. Food Agr. 33:407-413.

Hershey, D.R. 1988a. Measuring electrical conductivity with an inexpensive, digital, pocketsize meter. HortScience 23:402.

Hershey, D.R. 1988b. An inexpensive, pocket-size meter for measuring media $\mathrm{pH}$. HortScience 23:404.

Hershey, D.R. 1989. Improved equipment for vacuum extraction of saturated growing media. HortScience 24:155.

Hershey, D.R. and J.L. Paul. 1982. Leaching-losses of nitrogen from pot chrysanthemums with controlled-release or liquid fertilization. Scientia Hort. 17:145-152.

Kerr, G.P. and J.J. Hanan. 1985. Leaching of container media. J. Amer. Soc. Hort. Sci. 110:474-480.

Kofranek, A.M. and O.R. Lunt. 1975. Mineral nutrition, p. 36-46. In: A.M. Kofranek and R.A. Larson (eds.). Growing azaleas commercially. Div. Agr. Sci., Univ. California Publ. 4058.

Langhans, R.W. 1980. Greenhouse management. Halcyon Press, Ithaca, N.Y.

Lieth, J.H. and D.W. Burger. 1989. Growth of chrysanthemum using an irrigation system controlled by soil moisture tension. J. Amer. Soc. Hort. Sci. 114:387-392.

Maas, E.V. and G.J. Hoffman. 1977. Crop salt tolerance-Current assessment. J. Irr. Drainage Div., Amer. Soc. Civil Eng. 103:114134.

Marconi, D.J. and P.V. Nelson. 1984. Leaching of applied phosphorus in container media. Scientia Hort. 22:275-285.

Moore, D.P. 1974. Physiological effects of pH on roots, p. 135-151. In: E.W. Carson (cd.). The plant root and its environment. University Press of Virginia, Charlottesville.

Richards, L.A. (ed.). 1954. Diagnosis and improvement of saline and alkali soils. U.S. Dept. Agr. Agr. Hdbk. 60.

Sciaroni, R. H., R.L. Branson, J.M. Rible, R.F. Hasek, and R.S. Ayers. 1977. Water use on pot chrysanthemum can be cut. Calif. Agr. 31(5):42.

Yeager, T.H. and J.E. Barrett. 1986. Influence of an anion exchange resin on phosphorus and sulfur leaching from a soilless container medium. HortScience 21:152. 